\title{
Corpo e arte: uma proposta pedagógica na Educação Física a partir da bola de equilíbrio circense
}

Body and art: a pedagogical proposal about circus balance ball in Physical Education

\author{
Teresa Ontañón Barragán \\ Grupo de Estudo e Pesquisa das Artes Circenses (Circus), \\ Faculdade de Educação Física-Universidad Estatal de Campinas, Brasil \\ teonba@gmail.com
}

Daniel de Carvalho Lopes
Grupo de Estudo e Pesquisa das Artes Circenses (Circus), Universidad de São Paulo, Brasil
territio@gmail.com

Gilson Santos Rodrigues

Grupo de Estudo e Pesquisa das Artes Circenses (Circus),

Faculdade de Educação Física-Universidad Estatal de Campinas, Brasil

gio.sts.rodrigues@hotmail.com

\section{Leonora Tanasovici Cardani Gilson}

Grupo de Estudo e Pesquisa das Artes Circenses (Circus),

Faculdade de Educação Física-Universidad Estatal de Campinas, Brasil

norataca@hotmail.com

\author{
Marco Antonio Coelho Bortoleto \\ Grupo de Estudo e Pesquisa das Artes Circenses (Circus), \\ Faculdade de Educação Física-Universidad Estatal de Campinas, Brasil \\ bortoleto@fef.unicamp.br
}

\section{Resumo:}

Nos últimos anos o potencial pedagógico das atividades circenses vem atraindo a atenção de muitos professores de Educação Física, principalmente daqueles que atuam no contexto escolar, revelando uma aproximação que pode fomentar uma educação corporal em diálogo com a arte. No amplo repertório das práticas artísticas circenses, encontramos as modalidades de equilíbrio sobre objetos (funambulismo), dentre as quais se destacam o monociclo, a perna-de-pau, a corda-bamba, a bola de equilíbrio, o rolarola, entre outras, cuja prática constitui-se numa particular forma de diálogo com a estética do risco. Fundamentadas no domínio do equilíbrio corporal, essas práticas requerem especial atenção dos professores, visando o oferecimento de uma práxis pedagógica lúdica, envolvente, segura e que privilegie ainda sua dimensão expressiva. O presente artigo discute elementos basilares para o ensino da bola de equilíbrio, procurando, ademais, fomentar essa prática entre os profissionais que se aventuram no ensino das atividades circenses e que buscam uma Educação Física mais próxima à educação artístico-estética.

Palavras-CHave: Funambulismo, Circo, Bola chinesa, Pedagogia, Equilíbrio.

\section{RESUMEN:}

En los últimos años el potencial pedagógico de las actividades circenses viene atrayendo la atención de muchos profesores de Educación Física, principalmente de aquellos que actúan en el ámbito escolar, revelando una aproximación que puede fomentar una educación corporal en diálogo con el arte. Entre el amplio repertorio de prácticas artísticas circenses, encontramos las modalidades de equilibrio sobre objetos (funambulismo), entre las cuales se destacan el monociclo, los zancos, cuerda floja, bola de equilibrio, rola-bola, entre otras y cuya práctica se constituye en una particular forma de diálogo con la estética del riesgo. Fundamentadas en el dominio del equilibrio corporal, estas prácticas requieren especial atención de los profesores, visando ofrecer una praxis pedagógica lúdica, envolvente, segura y que privilegie además su dimensión expresiva. Este artículo discute elementos basilares para la enseñanza de la bola de equilibrio, buscando, además, fomentar esta práctica entre los profesionales que se aventuran en la enseñanza de las actividades circenses y que buscan una Educación Física más próxima a la educación artístico-estética.

Palabras Clave: Funambulismo, Circo, Bola china, Pedagogía, Equilibrio. 


\section{INTRODUÇÃO}

Dirigirse a todos, es ofrecer a cada uno la posibilidad de aprender tomando caminos diferentes. Esta necesaria diversidad nos obliga a encarar una multitud de prácticas susceptibles de ser utilizadas en las artes del circo (Fouchet, 2006, p. 25).

$\mathrm{Na}$ "arte equestre", vivida pela personagem Toby Tyler (Otis, 1970) de "O artista da fome" ${ }^{1}$ (Kafka, 2015), encontramos elementos simbólicos que revelam a espetacularidade secular do Circo, um amplo conjunto de possibilidades que têm atraído a atenção dos profissionais da Educação Física sobretudo devido à natureza corporal-expressiva dessa linguagem artística (Bolognesi, 2001; Mateu e Bortoleto, 2011). Esse Circo é constituído por uma enorme diversidade de práticas que foram sendo incorporadas, ressignificadas e produzidas, conformando paulatinamente uma particular forma de espetáculo, conforme revela a obra literária de Ramón Gómez de la Serna (1996).

Dentre os desdobramentos contemporâneos do Circo, a emergência de uma área que pode ser denominada "pedagogia das atividades circenses" (Bortoleto, Duprat e Tucunduva, 2016) pode ser percebida a partir de um conjunto de publicações que analisam a diversidade lúdico-estética, corporal-expressiva e simbólica do Circo buscando destacar seu potencial educativo (Invernó, 2003; Fouchet, 2006) e, em particular, debater sua aplicabilidade no âmbito da Educação Física (Bortoleto, 2010; Coasne, 2005).

No intuito de dar alento a essa "jovem" área de estudo, diversos pedagogos têm demostrado a riqueza da diversidade da linguagem circense expondo, entre outras possibilidades, um amplo espectro de atividades que compóem os saberes-fazeres típicos do espetáculo de Circo e que podem representar conhecimentos pertinentes a distintas áreas educativas (Bortoleto e Machado, 2003). Neste sentido, ao apresentar a diversidade como um dos princípios da pedagogia das atividades circenses (Ontañón, Bortoleto e Silva, 2013; Bortoleto, 2016; Ontañón, 2016), atentamos para uma práxis educativa (Ribas e Ferreira, 2014) capaz de ampliar as experiências e saberes dos alunos no que se refere ao Circo. Destarte, esperamos, com este estudo, criar mais argumentos para professores de Educação Física, mesmo entre os ainda resistentes, que tenham o desejo de dedicar-se ao ensino das atividades circenses (Ward, 2001).

Sem negligenciar os recentes debates sobre as distintas abordagens pedagógicas da Educação Física, optamos por uma perspectiva que parte do estudo da particular dinâmica das atividades circenses analisando suas estruturas sistémicas, isto é, as relações dialógicas e os componentes de suas lógicas internas (Parlebas, 2012; Bortoleto, 2017). Esta perspectiva não descarta nem desqualifica as proposições críticas e reflexivas sobre a prática circense. Pelo contrário, evidencia a importância de dialogar com conhecimentos de outras áreas constituindo-se numa efetiva práxis educativa (Fouchet, 2006; Invernó, 2003). Em suma, tratamos de apresentar um estudo específico (sobre o ensino de uma modalidade circense) permitindo aproximações com as abordagens pedagógicas, tarefa sobre a qual se debruçaram, por exemplo, Neves e Quaresma (2014), Gonçalves e Lavoura (2011) e Silva, Souza, Telles, Krug e Kunz (2016).

Nesta oportunidade, objetivamos abordar um subgrupo de modalidades circenses denominado "equilíbrio sobre objetos" (Duprat e Bortoleto, 2007), mais precisamente "equilíbrio sobre bolas gigantes". Neste sentido, discutimos brevemente o processo de constituição histórica dessa prática como produto da espetacularidade corporal e sobre seu processo de incorporação/ressignificação na arte de picadeiro, e, a seguir, debatemos certas noções conceituais no intuito de delinear o fenômeno investigado, tal como feito por Bortoleto e Calça (2007) com as modalidades aéreas. Parece-nos que os saberes e conhecimentos por nós apresentados podem trazer acréscimos às proposições didáticas já apresentadas por Aubin (1991), Gaquiere 
(1992), Simon (2000), Bertrand e Faivre (2000), Bortoleto (2003; 2004), Oberschachtsiek (2003), Fouchet (2006) e Equipe EP\&S da Charente-Maritime (2012). Em síntese, o presente estudo versa sobre o ensino da bola de equilíbrio com algumas proposições de jogos e atividades lúdicas específicas, destacando ademais elementos que visam reforçar a dimensão artístico-expressiva dessa prática (Sizorn, 2014; Mateu \& Bortoleto, 2011).

\section{O GLOBO SOB SEUS PÉS: O EQUILÍBRIO SOBRE A BOLA “INVADE" O PICADEIRO CIRCENSE}

As bolas de equilíbrio utilizadas comumente nos espetáculos circenses há mais de um século (Militello, 1978) recebem as mais variadas denominações: "bola gigante", "bola circense", "bola de equilíbrio" e, com maior recorrência, "bola chinesa". Esta última nomenclatura aponta para sua possível origem no país referente, mas, também, devido ao seu significativo desenvolvimento técnico e artístico encampado pelos asiáticos (Minghua, 1988). Ultrapassa nosso objetivo reconstruir a genealogia dessa prática ou dos diversos usos que foram dados a esse aparelho, no entanto, nos parece sintomático o fato de que os números circenses com bola são comumente desempenhados por artistas orientais, e que essa prática represente um importante exemplo da manutenção da estética do risco do circo clássico, na sua manifestação contemporânea (Goudard, 2009) ${ }^{2}$.

Em geral, as bolas de equilíbrio (Figura 1) são confeccionadas em fibra de vidro e podem medir de 60 a 120 centímetros de diâmetro, com peso variante de 9 a 35 quilos ${ }^{3}$. Importante ressaltar que existe uma relação proporcional do tamanho e peso do aparelho com a estabilidade oferecida em situação de equilíbrio, isto é, quanto maior o tamanho e o peso da bola, maior será a estabilidade para o equilíbrio sobre ela (Oberschachtsiek, 2003).

Figura 1: Bola de equilíbrio posicionada sobre pneus visando sua estabilidade
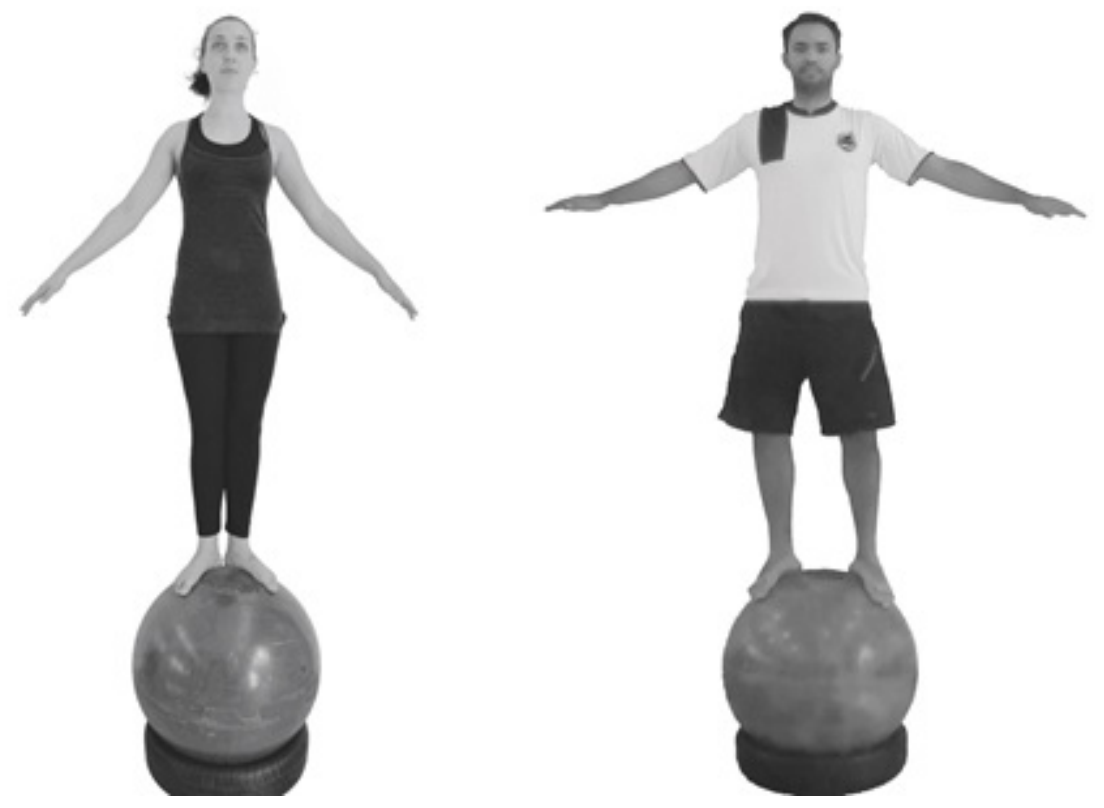

Especulamos que essa prática tenha se originado na dificuldade, desafio, encantamento e ludicidade de equilibrar-se sobre uma esfera, um elemento instável e "perigoso", representando um desafio ao domínio de si e do aparelho, num ato espetacular ("extra-cotidiano") e, por isso, pertinente ao Circo (Almeida, 2008). Possivelmente, este aspecto, somado a outros condicionantes, circunda o aparecimento das variadas modalidades de equilíbrio sobre objetos, como a perna de pau, o monociclo, a corda bamba (e suas variantes: o arame de equilíbrio e o slackline ${ }^{4}$, por exemplo), o rola-rola, etc. Além disso, parece-nos que a 
espetacularidade do "jogar-se ao acaso" (Caillois, 1990) - nesse caso sobre a instabilidade de uma esfera - sob o risco eminente de queda (que inclui até mesmo a possibilidade da morte) (Le Breton, 2009), acompanhada por uma "estética do risco" própria do Circo (Goudard, 2009), faz com que até hoje essa prática encante e fascine muita gente. Com efeito, quando presenciamos um equilibrista em pleno domínio de sua arte não percebemos nenhuma utilidade para seus feitos senão a busca por deleite, encantamento e beleza, conforme comenta Gómez de La Serna (1996):

Ante el perfecto equilibrista como ante otros artistas de circo, se piensa en cómo podrían ser utilizadas sus admirables facultades en algo trascendental, y no se encuentra la manera. Su trabajo es solo un trabajo de gracia, y, por ejemplo, si bien un buen equilibrista pasar de un lado a otro de un abismo yendo a buscar secretos del enemigo, se necesitaría que al otro lado hubiese alguien que fijase el otro extremo de la cuerda sobre el abismo, y necesitándose eso ya sería innecesaria del todo la audacia del equilibrista, porque bastaría un teléfono. (p. 349).

Devido ao exposto anteriormente, as modalidades de equilíbrio também permeiam o imaginário brasileiro sobre Circo (Rocha, 2016), conforme pode ser visto no quadro "Circo Trimilique", do programa televisivo brasileiro Castelo Ra-Tim-Bum ${ }^{5}$. Na referência supracitada, a representação mostra, entre outras coisas, a destreza de crianças no domínio do equilíbrio sobre objetos. Transcendendo as representações televisivas, o Circo supera seus próprios limites e se expande em possibilidades, de modo que é possível encontrar muitos espetáculos circenses que ofereciam/oferecem números ${ }^{6}$ de doma de animais (leões, tigres, elefantes, etc.) 7 com equilíbrio sobre objetos. Acreditamos que esses elementos (imaginário sobre o universo circense, destrezas humanas, doma de animais, etc.) ainda se constituem potentes "temas geradores" (expressão adaptada do pedagogo Paulo Freire) para as aulas de Circo (Chioda, 2018).

Outro aspecto significativo da arte circense é o processo de "hibridização" das modalidades de Circo (Bortoleto, 2017). Em outras palavras, refere-se à possibilidade de se comporem números artísticos mesclando distintas modalidades juntamente com a possibilidade de se compor o ato com outras linguagens artísticas (Peixoto, 2013), conformando o Circo como uma "Arte de Síntese" ou "Arte de Espetáculo", conforme discute Suassuna (2011). Noutros termos, o Circo oferece ao artista ou praticante a possibilidade de somar ao equilíbrio sobre bola, por exemplo, outras práticas como modalidades malabarísticas (manipulações de distintos objetos), clownescas, acrobáticas, etc. A título de ilustração, citamos o número da artista Marion Brede, de origem alemã e radicada no Brasil (Campinas, SP), que, "em pé" sobre a bola, segurava uma faca à boca e, apoiada em sua lâmina, equilibrava uma espada de ponta fina ${ }^{8}$.

Essas possibilidades estéticas e artísticas, entendidas a partir de sua variedade conceitual e dos múltiplos sentidos e significados que se podem dar à sua prática, tal e como pincelamos acima, constituem-se importantes temas geradores para abordar a temática circense (Miranda e Bortoleto, 2018). Contudo, acreditamos ser insuficiente o simples acúmulo de informações sobre a modalidade, e por isso fomentamos também a incorporação de saberes de como realizar a prática (saber-fazer), conforme atesta Oberschachtsiek (2003). Nesse sentido, abordamos a seguir alguns aspectos que envolvem o processo de ensino-vivênciaaprendizagem dessa modalidade.

\section{CONHECENDO E RECONHECENDO A BOLA DE EQUILÍBRIO}

$\mathrm{Na}$ esfera conceitual, podemos compreender o equilíbrio de diferentes perspectivas que se estendem desde a Física newtoniana (Resnick, Halliday e Walker, 2011) ${ }^{9}$ à poética circense (Goudard, 2009). Isso mostra a possibilidade de abordar o Circo nos espaços educativos como um tema interdisciplinar (Costa, Tiaen e Sambugari, 2008), integrando diferentes disciplinas em torno do mesmo tema, como no exemplo exposto por Ward (2001), que numa aula de Física adotou a manipulação de objetos (malabares de lançamento) como tema gerador. Destarte, pautamo-nos no ponto de vista da aprendizagem motora a qual define equilíbrio como "[...] a habilidade de um indivíduo manter a postura de seu corpo inalterada, mesmo quando é colocado 
em várias posições. O equilíbrio é básico para todo movimento e é influenciado por estímulos visuais, táteis, cinéticos e vestibulares" (Gallahue e Ozmun, 2003, p. 346).

Atentando-se às modalidades de equilíbrio, especificamente à bola de equilíbrio ${ }^{10}$, é importante tratarmos dos elementos que possibilitam ao praticante manter-se em situação de equilíbrio. Da mesma maneira que ocorre em outros aparelhos, para manter-se equilibrado é necessário que o centro de massa $(\mathrm{CM})^{11}$ do praticante, localizado aproximadamente na região do abdômen, estando ele em qualquer posição (sentado, em pé, deitado, ajoelhado, etc.), esteja alinhado diretamente com o eixo central da bola, isto é, seu núcleo. Em caso de desalinhamento do CM do corpo praticante em relação ao eixo central do aparelho, o praticante sairá da posição de equilíbrio e, consequentemente, cairá da bola.

Em outras palavras, quando o praticante, equilibrando-se com os dois pés sobre a bola, flecte seu tronco para frente (ou para outra posição) ou move os braços ou a cabeça, consequentemente desloca seu centro de massa no mesmo sentido (deslocamento à frente) e provoca, como resultado, o desalinhamento do seu CM com o "núcleo" da bola. Resultante dessa ação é possível visualizar que o praticante será impelido a reorientar sua posição corporal, descer ou, caso não reaja a tempo, cairá (Ricken, 2001).

Ainda tratando da dimensão conceitual, ressaltamos a distinção entre dois tipos de equilíbrio. O primeiro envolve a manutenção do equilíbrio enquanto o centro de gravidade ou CM permanece estacionário, o qual se denomina equilíbrio estático. O segundo, denominado equilíbrio dinâmico, envolve a manutenção do equilíbrio conforme o centro de gravidade se desloca (Gallahue e Ozmun, 2003). Sobre a bola, o equilíbrio dinâmico representa a capacidade de manter o alinhamento do $\mathrm{CM}$ - núcleo da bola enquanto se deslocam ambos, bola e equilibrista (funambulista). Além dessa tipologia, é importante ressaltar as possibilidades de movimentos axiais, isto é, posturas estáticas que envolvem inclinações, alongamentos, giros, rotações, etc., sobre a bola, de modo que é comum equilibrar-se de diversas maneiras, como, por exemplo, sentado, deitado, agachado, de costas, etc. Inclusive, é possível equilibrar-se com as mãos (parada de mãos) ou com a cabeça (parada de cabeça) sobre a bola, em casos de exímia destreza e controle.

Outro aspecto conceitual que merece atenção, conforme Fouchet (2006), diz respeito à distinção entre equilíbrio geral e específico e ao princípio pedagógico da transferência de aprendizagem (Parlebas, 2001). Para o autor, não existe equilíbrio geral que possa ser transferido a distintas práticas funambulescas, pois no plano informacional sinestésico observam-se diferenças significativas que exigem a vivência do equilíbrio específico de cada modalidade. Desse modo, o domínio do equilíbrio sobre a perna de pau, por exemplo, não garante o domínio sobre o rola-rola ou na bola de equilíbrio (Bortoleto, 2003). Assim, sugerimos que cada praticante vivencie as diferentes etapas de aprendizagem específicas à modalidade (Fouchet, 2006).

Nos parece ainda, que o avanço demasiado rápido respeito as etapas de aprendizagem ou a alegação de transferência de aprendizagem de equilíbrio geral com relação aos específicos, representam uma conduta pedagógica que pode expor os praticantes à sérios riscos, sobretudo, à integridade física dos mesmos, além de frustações frente ao processo pedagógico.

Em nível procedimental, atentamos para elementos referentes à lógica interna da prática (organização do espaço de vivências e preparação do material), entrelaçando-a com outros aspectos fundamentais, como a segurança e as ações motrizes típicas (comentando algo sobre algumas técnicas corporais). No tocante às ações motrizes, destacaremos aspectos do plano informacional e técnico, mas também citaremos algumas reflexões que visam promover uma prática segura e que fomente a expressividade e diversidade estética que caracterizam o circo. Evidenciar esses aspectos é atentarmos para a intencionalidade pedagógica em busca de uma efetiva práxis educativa.

Como em qualquer modalidade circense que se pretenda ensinar, a organização do espaço de prática é fundamental, desse modo, o uso de colchões e/ou solo acolchoado (tatames de Etil Venil Acetato ou E.V.A., por exemplo) é recomendado. Além disso, é importante não ter objetos como bancos e cadeiras próximos aos praticantes durante a realização das tarefas, pois na real possibilidade de queda do aparelho e aterrissagem 
sobre tais objetos as chances de um acidente de graves proporções aumentam consideravelmente. Neste sentido, é preciso garantir um espaço livre entre cada bola e o praticante.

O mesmo cuidado é necessário no uso de ajudas manuais como estratégia didática. Elas podem ser realizadas pelos próprios participantes e/ou pelos professores, de modo similar ao proposto por Araújo (2012) quando discute o ensino da Ginástica Artística.

Em relação ao material, é importante mencionar a dificuldade de aquisição da bola, sendo ela encontrada em poucas lojas especializadas e muitas vezes com altos valores, fato semelhante ao contexto francês, conforme mencionado por Fouchet (2006). Todavia, Munhoz e Ramos (2008) afirmam que a durabilidade do aparelho/equipamento e sua acessibilidade são elementos a serem considerados especialmente quando nos referimos à realidade escolar. Deste modo, as decisões sobre a aquisição do aparelho dependerão sobretudo da sensibilidade, criticidade e dos recursos de que cada instituição/profissional disponha.

Em caso de viabilidade de aquisição do material, sugerimos a atenção aos seguintes aspectos: em geral, a bola é construída de "fibra de vidro" ou resina similar, totalmente rígida e com uma superfície lisa. Ela também possui peso elevado e não possui nenhuma maleabilidade, sendo essas as características que garantem maior estabilidade e controle do praticante, além de maior durabilidade do aparelho. Em alguns casos, sugerimos, em consonância a Oberschachtsiek (2003), que a bola seja revestida por algum tipo de elemento antiderrapante (borracha, E.V.A., etc.). Neste sentido, nossa experiência vem mostrando que colar na bola um círculo de EVA $(2 \mathrm{~mm})$ ou outro material aderente, em duas extremidades, de modo a sinalizar o "lugar" mais adequado para o praticante posicionar-se e ao mesmo tempo evitar "escorregões" sobre a bola, é um cuidadoso detalhe que qualifica as vivências. Esse tipo de revestimento garante maior aderência do aparelho aos pés do praticante e maior atrito ao solo, constituindo-se num importante recurso didático para aprendizagem dos praticantes. Além disso, essa "proteção" ajuda ainda a proteger a bola de pequenos golpes comuns no uso cotidiano.

Pensando no desenvolvimento pedagógico, sugerimos, em consonância com Ricken (2001) e Oberschachtsiek (2003), a utilização de aparelhos alternativos (muitas vezes mais acessíveis e mais em conta) com melhor custo-benefício. Dentre eles, os carretéis de madeira usados para o armazenamento e transporte de cabos elétricos (Figura 2) ou os barris industriais, sugeridos por Fouchet (2006), são boas opções. Além desses, Munhoz e Ramos (2008) relatam a possibilidade de utilização de tambores metálicos (de armazenamento de líquidos). Todavia, esses tambores costumam ser mais leves e "amassar" mais facilmente, por isso os carretéis de madeira ainda nos parecem a melhor opção. É possível, a partir desses carretéis, construir um "rolo gigante" (Figura 3), cujo uso ajudará significativamente no domínio futuro da bola de equilíbrio.

Figura 2: Exemplo de carretel de madeira

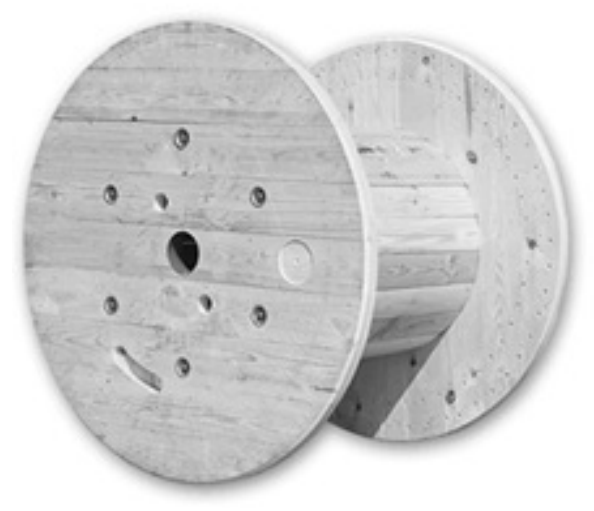

Esses aparelhos, independentemente da possibilidade de aquisição da bola de equilíbrio, são muito aproveitáveis, pois servem como recurso de introdução ao ensino da modalidade. Eles permitem 
deslocamentos apenas para frente ou para trás, e precisamente essa característica ajuda o praticante a manterse em equilíbrio de modo mais fácil em comparação com a bola cujo deslocamento ocorre em todas as direções (Ricken, 2001). A lógica de ação, isto é, o deslocamento sobre esses equipamentos exige as mesmas condutas motrizes que são exigidas para o deslocamento sobre a bola. Dessa maneira, esses aparelhos constituem-se importantes alternativas pedagógicas, além de seu potencial crítico/reflexivo de discussão sobre a adaptação/ ressignificação de materiais cotidianos.

Sobre o uso dos materiais alternativos é interessante mencionar o estudo realizado por Ontañón (2016) numa escola francesa na qual o professor procurava, por meio das atividades propostas, encorajar os alunos de maneira que pudessem participar de um processo de criação artística por meio da descoberta e exploração dos diversos objetos, entre os que encontrávamos tambores, bancos, ou mesmo, carrinhos de supermercado. A proposta deste professor não se restringia ao ensino técnico de habilidade de equilíbrio, mas na busca de novas formas de equilíbrio corporal, observando as possibilidades e limitações dos objetos sobre os quais os alunos se equilibravam, tratando assim, de fomentar o desenvolvimento de outras possibilidades poéticas e estéticas, no sentido defendido por Sizorn (2014).

Uma questão importante, quando nos referimos à prática de bola de equilíbrio, carretéis, tambores ou rolos gigantes, assim como de qualquer outro aparelho de equilíbrio (perna de pau, monociclo, etc.), é a segurança, já que a prática destas atividades oferece certos riscos - sobretudo físicos - aos praticantes. As possibilidades de quedas são grandes em função da altura do chão e da velocidade de deslocamento. Por isso, essas práticas podem ocasionar lesões graves se as devidas medidas de segurança não forem tomadas. Assim, aconselhamos permanente atenção, cuidado e responsabilidade de mestres e aprendizes durante as vivências. Sugerimos a adoção de várias estratégias pedagógicas que garantam a segurança dos praticantes e reforçamos a importância da utilização de diferentes formas de ajuda (manuais e instrumentais): uso de colchões para diminuir a mobilidade da bola, uso de uma base de pneu para dar estabilidade ao aparelho, corredores de colchões para o deslocamento, etc.

Visando fomentar uma cultura de segurança como sugerido por Ferreira, Bortoleto e Silva (2015) quando se referem à prática circense, assim como focar no ensino da segurança ativa como sugerem Mauriceau, Simon, Charlier, Avisse e Lagrange (2012) quando se referem especificamente ao contexto escolar, aconselhamos que os educadores instruam seus aprendizes sobre as medidas de segurança e ajudas manuais. Essa conduta pedagógica permite abordar valores e atitudes que visem responsabilizar os aprendizes pela própria segurança e a dos colegas. Além disso, sugerimos a proposição de ateliês (Fouchet, 2006; Invernó, 2003; Ontañón e Bortoleto, 2014) como estratégia para evitar o problema das filas, conforme comentado por Munhoz e Ramos (2008). Entretanto, parece-nos que os ateliês serão eficientes somente quando o corpo discente incorporar os procedimentos de segurança da modalidade. 
Figura 3: Carretel com ajuda

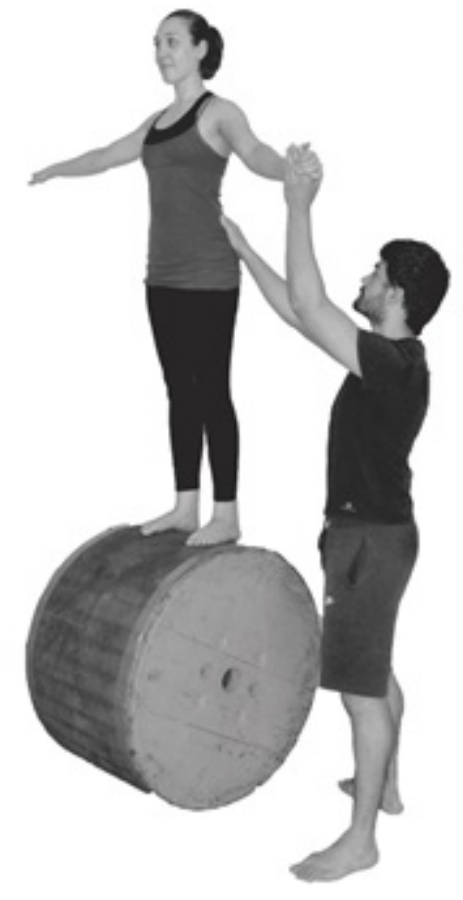

Neste contexto, enxergamos as atividades circenses não apenas como uma possibilidade de vivenciar as acrobacias, os malabares ou os equilíbrios corporais, mas como uma oportunidade de contribuir com a educação estético-artística, que frequentemente é ignorada nas aulas de Educação Física Escolar (Coasne, 2005; Ontañón, 2016). Ao adotarmos essa premissa, o ensino da técnica continua sendo necessário, contudo o fomento da expressividade e da criatividade adquire centralidade. Não obstante, nossa experiência de mais de uma década nessa área em particular indica que muitos professores ainda carecem dos recursos pedagógicos necessários para abordar as atividades circenses, animando-nos a apresentar mais adiante algumas ferramentas que possam ajudar no ensino da bola de equilíbrio em suas aulas.

Em todas as modalidades de "equilíbrio sobre objetos", devemos dar ênfase ao controle postural, à propriocepção e, no caso da bola de equilíbrio, ao contato da região plantar dos pés do praticante com a bola. Assim, deve-se instruir o aprendiz a evitar olhar para os próprios pés/bola, uma vez que essa conduta resultaria numa postura não favorável para o equilíbrio. Sobre a bola de equilíbrio, a força motriz necessária ao deslocamento em qualquer direção é contrária ao sentido de orientação do equilibrista. Desse modo, buscando o deslocamento do equilibrista para frente, tratamos de realizar pequenos "passos" alternados sobre a bola com a intenção de fazê-la rolar para frente (lembrando-se o praticante de manter o alinhamento entre o CM e o núcleo da bola). Para isso, o movimento dos pés na superfície esférica se assemelha ao nosso caminhar para trás ("passos de pinguim") (Figura 4).

Vale mencionar que esses "passos" sobre o aparelho não se dão da mesma maneira que os da caminhada em um pavimento imóvel. Eles são mais uma ação de "empurrar" a bola para as laterais, no caso de se ficar parado sobre o aparelho num mesmo lugar, ou de "empurrar" a bola para frente, no caso de a intenção ser a de deslocamento para trás. Novamente, reafirmamos que para que haja êxito nessa modalidade é essencial que o CM do praticante esteja permanentemente alinhado com o centro da bola, favorecendo o equilíbrio e evitando quedas. 
Figura 4: Detalhe da posição de “passos de pinguim” sobre a bola

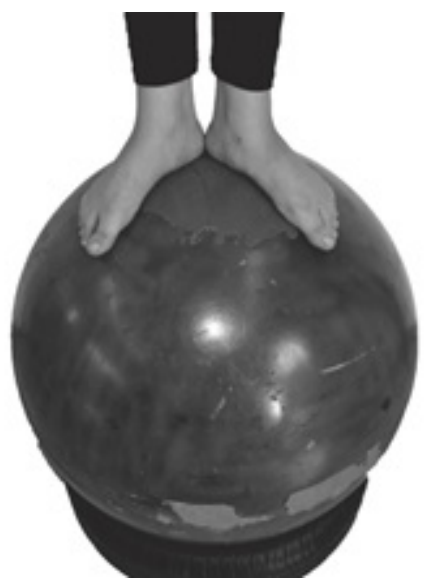

A técnica básica para permanecer sobre a bola num mesmo local é o praticante manter-se permanentemente realizando leves e pequenos "passos" laterais sobre a bola, ou seja, fazer com que ela faça pequenos deslocamentos de um lado para outro numa amplitude bem curta. Esse movimento dos pés na superfície da bola facilita o equilíbrio dinâmico com o aparelho, pois o equilíbrio estático - o ficar estritamente parado em sua superfície - é "quase impossível”, já que a bola oscila em todos os sentidos/ direções.

Quando disponíveis, as “bolas de pilates” (de borracha e flexíveis) mostram-se um recurso didático capaz de criar um conjunto de possibilidades que podem facilitar o domínio do corpo sobre a bola. Atinente a essa intenção, sugerimos que sejam realizadas tarefas simples, em nível elementar de exigência de habilidades. Assim, propomos tarefas básicas, como, sobre a "bola de pilates", buscar o equilíbrio sentado, em três/ quadro/cinco ou seis apoios, ou ainda em decúbito frontal ou dorsal (Figura 5). De resto, partilhamos, a seguir, encorajados por nossas experiências docentes com a modalidade e embasados nas indicações trazidas anteriormente, algumas possibilidades para uma proposta de ensino-vivência-aprendizagem com a bola de equilíbrio em nível de iniciação e acrescida da ludicidade como pressuposto das aulas (Bortoleto, Pinheiro e Prodócimo, 2011).

Figura 5: Exemplo de exercício com a "bola de pilates" (flexível) com vários apoios
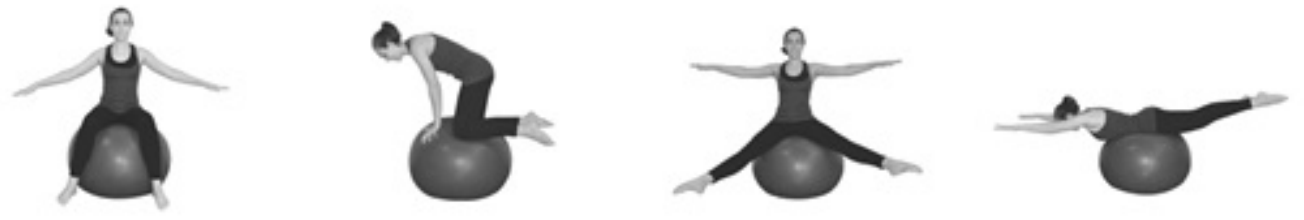

Visando contribuir para pedagogos que se aventurem no ensino dessa modalidade, propomos, a seguir, algumas atividades que pudemos realizar e aprimorar ao longo de mais de dez anos de experiência. Cabe destacar que como tratamos de ressaltar ao longo deste trabalho, o objetivo principal se encontra em fomentar a expressividade e criatividade dos praticantes, porém ampliar o repertorio de possibilidades se faz necessário quando tratamos de práticas ainda incipientes no campo da Educação Física.

ATIVIDADE 1: Descobrindo o equilíbrio sobre objetos

Objetivo: diferençar o equilíbrio de objetos (manipulação) do equilíbrio sobre objetos (funambulismo). Desenvolvimento da atividade: demonstrar aos alunos por meio de imagens (fotos, vídeos, etc. ${ }^{12}$ ) diferentes formas de equilíbrio sobre objeto(s) (perna de pau, rola-rola, monociclo, etc.) e discutir a diferença da prática de equilíbrio de objetos (manipulação). Contextualizar histórica e esteticamente à 
modalidade e suas múltiplas possibilidades, bem como sua possível contribuição para o desenvolvimento corporal, como sugerem Invernó (2003), Fouchet (2006) e Bortoleto e Machado (2003).

A seguir, propomos algumas atividades elementares (sequência de situações) que visam ao início da busca do controle do corpo sobre a bola chinesa:

Exercício 1: Subir e descer da bola (fixa com uso de pneu como base de apoio), realizado individualmente, em duplas ou trios (Figura 6).

Figura 6: Exercício 1 (com a bola posicionada sobre um pneu); Exercício 2 (com um ajudante e colchões nos lados e com dois ajudantes); Exercício 3 (com a bola dentro de um corredor de colchões e sem ajudas nem apoio para a bola).
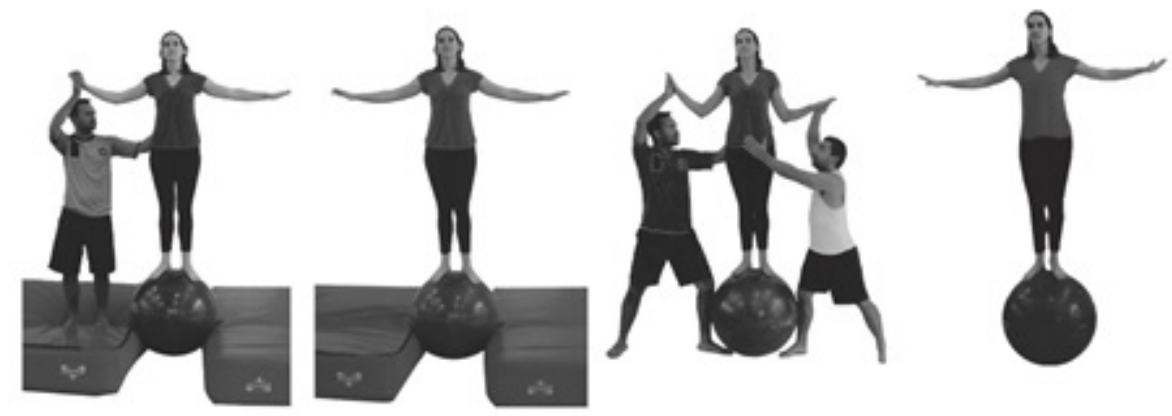

Exercício 2: Subir e descer com a bola solta com a ajuda de uma pessoa ou duas e/ou com proteção de colchões ao lado da bola. Importante ressaltar que os ajudantes podem dar uma das mãos ao praticante e a outra pode ser posicionada levemente nas costas, caso o praticante se desequilibre para trás. No caso de dois ajudantes um fica com a mão posicionada nas costas e o outro na frente do praticante (Figura 6).

Exercício 3: Mover-se e girar sobre a bola - subir na bola e experimentar mudar de posição; brincar com o equilíbrio com ajuda;

Exercício 4: Avançar para frente (no corredor de colchões);

Exercício 5: Andar para atrás (no corredor de colchões);

Exercício 6: Andar lateralmente (no corredor de colchões).

Exercício 7: Agachar e tocar a bola com as mãos;

Exercício 8: Variações e combinações diversas: malabares com três bolinhas (Figura 7).

Figura 7: Variações e combinações diversas
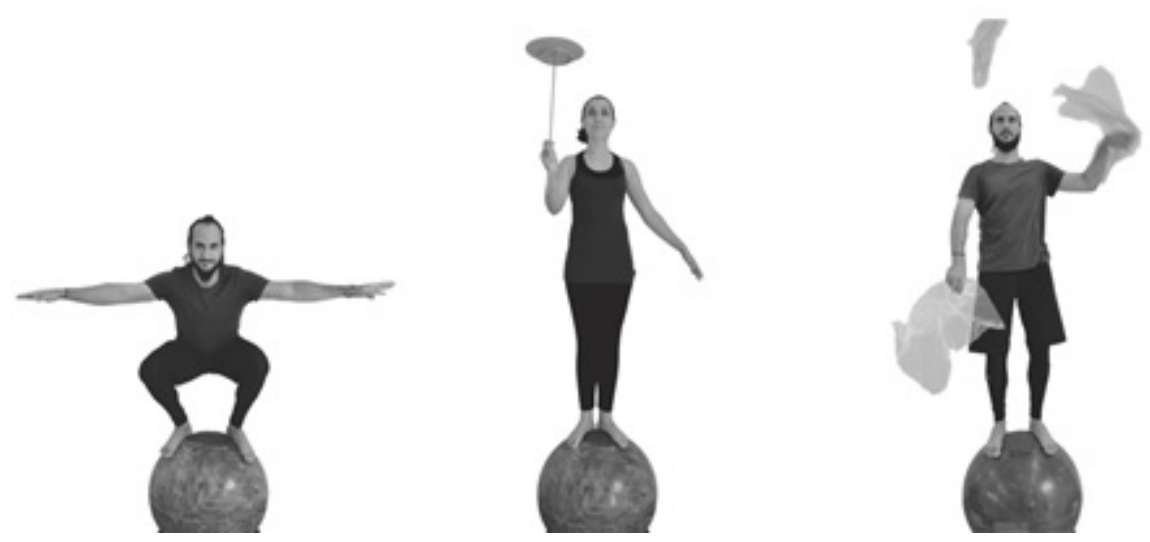
ATIVIDADE 2: Jogando e brincando com a bola gigante

Jogo 1 - O abacaxi: O início do jogo ocorre a partir do exercício 1 (Figura 6) e consiste numa situação em que vários participantes sobem numa mesma bola de maneira simultânea (ou sequencial). O objetivo é permanecer em equilíbrio sobre o aparelho por determinado período.

Pode-se começar com dois participantes e ir aumentando até se conseguir o maior número possível (jogo proposto por Bortoleto, Pinheiro e Prodócimo, 2011).

Jogo 2 - A estátua: propõe-se (desafia-se) a realização de movimentos axiais. Equilibrando-se sobre a bola, o praticante realiza diversas poses que o professor ou os companheiros indicarem (desafiarem), como, por exemplo, posições acrobáticas do avião (figura 8), rã, etc., e para cada pose o participante deverá manter-se em estado de equilíbrio por certo período.

Uma variação interessante é o jogo/brincadeira popularmente denominado "O mestre mandou", que pode coadunar com a proposição de movimentos axiais sobre o aparelho. Nossa experiência vem mostrando que esse jogo é capaz de engajar as crianças na atividade de forma satisfatória, pois as envolve em situações de autodesafios.

Figura 8: Jogo da estátua - Avião com ajuda

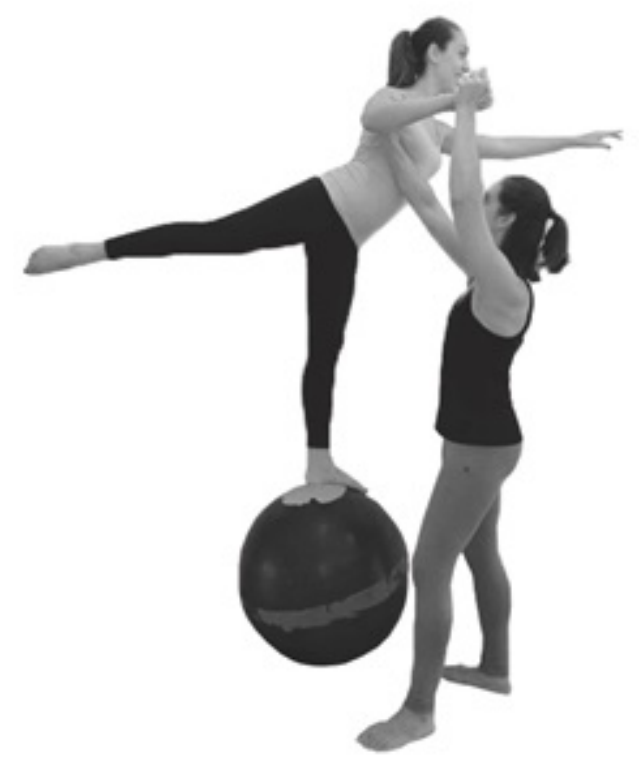

Jogo 3 - Passing: Duas pessoas equilibradas sobre bolas tentarão trocar objetos (como bolas ou claves de malabares) entre si sem deixarem cair no chão.

Jogo 4 - Circulando: Tendo por base o tipo de conduta motriz mostrado anteriormente no exercício 4, é delimitado no chão (ou num espaço acolchoado) um percurso a ser realizado andando sobre a bola. Ademais, podem-se, dependendo do nível de domínio do aparelho por parte dos participantes, acrescentar diversos objetos no percurso. Esses objetos poderão ficar dispostos no circuito e exigirá deslocamentos em diversas direções, saliência, ou diversos desníveis, aclives, etc. (jogo sugerido por Invernó, 2003).

Em ambas as atividades acima descritas, recomendamos uma exploração ampla e diversa das possibilidades corporais, para além dos exemplos indicados. Tanto do ponto de vista técnico, como do estético, e ainda do pedagógico (processo), sempre podemos buscar novas e diferentes opçóes (Gaquière, 1992; Fouchet, 2006; Coasne, 2005, Bortoleto, 2003). Individualidades e ações espontâneas devem ser valorizadas visando maior liberdade de expressão (Sizorn, 2014), assim como as formas de organização "abertas" (auto-gestão) das atividades com participação ativa dos alunos (Invernó, 2003). De fato, a co-responsabilização na gestão 
das atividades, e, consequentemente do risco que elas podem oferecer, pode ajudar no aumento da segurança como defendem Mauriceau et al (2012). Mais ainda, a prática da bola de equilíbrio nos coloca em contato direto com o risco, e consequentemente, experimentando de um modo mediado a "estética do risco" que, como dissemos envolve o circo contemporâneo (Goudard, 2009). Com isso, estaremos contribuindo para construção uma percepção subjetiva do risco baseada na experiência, e não somente na contemplação à distância.

\section{CONSIDERAÇÕES "POR AGORA"}

Conforme dissemos, partimos de um objetivo primário, que é ampliar o debate pedagógico no sentido de uma abordagem mais diversificada das atividades circenses quando tratada no âmbito escolar. De acordo com o que já foi mencionado por Ontañón, Duprat e Bortoleto (2012), os relatos de experiências nesse campo se resumem às modalidades circenses mais conhecidas, dentre as quais a bola de equilíbrio não faz parte. No entanto, o circo é uma arte que, por sua variedade, apresenta muitas outras possibilidades, incluindo as mais “conhecidas", como os malabares com bolas ou claves (Duprat e Bortoleto, 2007). Nesse sentido, nosso desafio é, também, ampliar esse reportório, como nesse caso, com o ensino da bola de equilíbrio, mostrando múltiplas oportunidades para os professores de Educação Física.

Logo, a formação de arte-educadores e professores de Educação Física no âmbito específico dos equilíbrios sobre objetos, razão que motivou o presente trabalho, mesmo que ainda represente os primeiros passos em direção a uma pedagogia da bola de equilíbrio. Por isso nossa preocupação no detalhamento do aparelho, a redobrada atenção às questões didáticas e, sobretudo, a redundância na exposição das questões de segurança. Isso, sem deixar de dar atenção com à dimensão artístico-expressiva dessas práticas (Mateu e Bortoleto, 2011).

Estamos cientes dos limites das proposições apresentadas e das dificuldades de toda ordem quanto às especificidades do cotidiano de cada educador. Entretanto, entendemos que o sistematizar e compartilhar de nossas experiências pode ajudar outros profissionais a superarem as dificuldades que porventura possam aparecer no trato com o Circo no contexto escolar. Com efeito, toda vez que tomamos conhecimento de alguém dando materialidade à pedagogia das atividades circenses sentimos a necessidade de dialogar (trocar informações e experiências), e foi essa motivação que norteou este trabalho.

Por fim, esperamos que o mesmo espírito expresso por Freire (2011, p. 10), de que "cada vez que aparece um livro [artigo, relato de experiência...] assim, meu apetite por dar aulas aumenta, [...]", possa inspirar e encorajar outros arte-educadores e professores de Educação Física na busca por uma efetiva práxis educativa com a temática circense. Por essa razão, embora não seja usual, deixamos algumas referências que podem contribuir para a ampliação do que aqui conseguimos expor:

\section{REFERENCIAS}

Araújo, C. M. R. (2012). Manual de ajudas em ginástica. Várzea Paulista, SP: Fontoura.

Aubin, S. (1991). Jouer avec son équilibre. Revue EPS 1(54).

Bertrand, P.; e Faivre, A. (2000). J'apprends à... me déplacer sur la boule. Revue EPS, (97).

Bolognesi, M. F. (2001). O corpo como princípio. Trans/Form/Ação, (24), 108-112.

Bortoleto, M. A. C.; e Machado, G. A. (2003). Reflexões sobre o Circo e a Educação Física. Corpoconsciência, 2(12), 36-69.

Bortoleto, M. A. C. (2003). A Perna de Pau circense: o mundo sob outra perspectiva. Motriz, 9(3), 125-134.

Bortoleto, M. A. C. (2004). Rola-bola: iniciação. Movimento \& Percepção, 4(4-5), 100-109.

Bortoleto, M. A. C.; Calça, D. H. (2007). Circo e educação física: compendium das modalidades aéreas. Movimento \& Percep̧̧ão, 8(11), 345-360. 
Bortoleto, M. A. C. (Org.). (2008). Introdução à pedagogia das atividades circenses. Jundiaí, Brasil: Fontoura.

Bortoleto, M. A. C. (Org.). (2010). Introdução à pedagogia das atividades circenses (Vol. 2). Várzea Paulista, Brasil: Fontoura.

Bortoleto, M. A. C.; Pinheiro, P. H. G.; e Prodócimo, E. (2011). Jogando com o circo. Jundiaí, Brasil: Fontoura.

Bortoleto, M. A. C., Duprat, R. M., e Tucunduva, B. B. P. (2016). As atividades circenses na FEF-Unicamp: a construção de uma nova área de estudos e pesquisa. In M.A.C. Bortoleto, T.B. Ontañón e E. Silva, Circo: Horizontes educativos (pp. 225-257). Campinas: Autores Associados.

Bortoleto, M. A. C. (2017). Um encontro entre o funâmbulo e o praxiólogo: ideias para mestres e discípulos. In L.A. Ferreira e G.N.S. Ramos, Educação Fisica Escolar e Praxiologia Motriz: compreendendo as práticas corporais (pp. 55-79). Curitiba, Brasil: CRV.

Caillois, R. (1990). Os jogos e os homens: a máscara e a vertigem. Lisboa, Portugal: Cotovia.

Chioda, R. A. (2018). Uma aventura da alegria e do risco: narrativas de um professor de educação física sobre o ensino das atividades circenses (Tese Doutorado em Educação Física). Universidade Estadual de Campinas, Faculdade de Educação Física. Orientador: Marco Antonio Coelho Bortoleto. Campinas, Brasil.

Sizorn, M. (2014). Le cirque à l'épreuve de sa scolarisation. Artification, légitimation... normalisation? Staps, 103(1), 23-38.

Coasne, J. (2005) Enseigner les arts du cirque. Revue EPS, 313, 39-44.

Costa, A. C. P.; Tiaen, M. S.; e Sambugari, M. R. N. (2008). Arte circense na escola: possibilidade de um enfoque curricular interdisciplinar. Olhar de professor, 11(1), 197-217.

Duprat, R. M.; e Bortoleto, M. A. C. (2007). Educação Física escolar: pedagogia e didática das atividades circenses. Revista Brasileira de Ciências do Esporte, 28(2), 171-189.

Equipe EP\&S de la Charente-Maritime. (2012). En equilibre sur la boule. Revue EP\& S (Cabier 3 à 12 ans), 350, 11.

Ferreira, D. L.; Bortoleto, M. A. C.; e Silva, E. (2014). Segurança no circo: questão de prioridade. Várzea Paulista: Fontoura.

Freire, J. B. (2011). Prefácio. In M.A.C. Bortoleto, P.H.G. Pinheiro e E. Prodócimo, Jogando com o circo (pp. 9-10). Jundiaí, Brasil: Fontoura.

Fouchet, A. (2006). Las Artes del Circo: una aventura pedagógica. Buenos Aires: Stadium.

Gallahue, D. L. e Ozmun, J. C. (2003). Habilidades motoras fundamentais. In D.L. Gallahue, J.C. Ozmun, M.A. da Silva Pereira Araujo (trad.) Compreendendo o desenvolvimento motor: bebês, crianças, adolescentes e adultos. São Paulo, Brasil: Phorte.

Gaquière, R. (1992). L'équilibre à l'école. Revue EPS, 1, 59.

Gómez de la Serna, R. (1996). El Circo. In R. Gómez de la Serna, Obras completas. Barcelona, España: Círculo de Lectores: Galaxia Gutenberg.

Gonçalves, L. L.; e Lavoura, T. N. (2011). O circo como conteúdo da Cultura Corporal na Educação Física escolar: possibilidades de prática pedagógica na perspectiva histórico-crítica. Revista Brasileira Ciência e Movimento, $19(4), 77-88$.

Goudard, P. (2009). Estética do risco: do corpo sacrificado ao corpo abandonado. In E. Wallon (Org.), O circo no risco da arte (pp. 25-31). Belo Horizonte, Brasil: Autêntica.

Invernó, J. (2003). Circo y educación física: otra forma de aprender. Barcelona, España: INDE.

Kafka, F. e Silva Braga, G. da (trad.) (2015). Um artista da fome seguido de Na colônia penal \& outras histórias. Porto Alegre, Brasil: L\&PM.

Le Breton, D. (2009). Condutas de risco: dos jogos de morte ao jogo de viver. Campinas, Brasil: Autores Associados.

Mateu, M. S., e Bortoleto, M. A. C. (2011). La lógica interna y los dominios de acción motriz de las situaciones motrices de expresión (SME). Emancipação, 11(1), 129-142.

Mauriceau, É.; Simon, V.; Charlier, C.; Avisse, M.; e Lagrange, C. (2012). La sécurité active: êntre responsable de soi et de ses partenaires. Revue EPS (Cahier 12 ans et plus). 
Militello, D. T. (1978). Picadeiro. São Paulo, Brasil: Edições Guarida.

Minghua, H. (1988). Las cien diversiones: dos mil años de inagotable acrobacia china. In Correo de la Unesco, El circo: un espectáculo del mundo (pp. 8-9).

Miranda, R. C. F.; Bortoleto, M. A. C. (2018) O circo na formação inicial em educação física: um relato autoetnográfico. Revista Brasileira de Ciências do Esporte, 40(1), 39-45.

Munhoz, J. F.; e Ramos, G. N. S. (2008). O circo nas aulas de educação física: sua aplicação em uma escola pública no estado de São Paulo. In Anais II Seminário de Estudos em Educação Física Escolar (pp. 255-292). São Carlos, Brasil: CEEFE/UFSCar.

Neves, M. R.; e Quaresma, F. N. (2014). Hoje tem goiabada? Não! Hoje tem marmelada? Não! O que temos então? Estudos Culturais em Ação. In M.G. Neira; M.L.F. Nunes e M.E. Lima (Orgs.), Educação física e culturas: ensaios sobre a prática (Vol. II, pp. 135-149). São Paulo, Brasil: FEUSP.

Oberschachtsiek, B. (2003). Jonglieren und mehr... Handbuch Bewegungskünstefür Schule, Verein und Freizeit. Aachen: Meyer und Meyer.

Ontañón, T. B., Duprat, R. M., e Bortoleto, M. A. C. (2012). Educação Física e atividades circenses: "O estado da arte". Movimento, 18(2), 149-168.

Ontañón, T. B.; Bortoleto, M. A. C.; e Silva, E. (2013). Educación corporal y estética: las actividades circenses como contenido de la educación física. Revista Iberoamericana de Educación, 62, 233-243.

Ontañón, T. B.; e Bortoleto, M. A. C. (2014). Todos a la pista: el circo en las clases de educación física. Apunts Educación Física y Deportes, 115, 37-45.

Ontañón, T. B. (2016). Circo na escola: por uma educação corporal, estética e artística (Tese Doutorado), Universidade Estadual de Campinas, Faculdade de Educação Física, Campinas, Brasil.

Otis, J. (1970). Dez semanas num circo (Toby Tyler). Rio de Janeiro, Brasil: Ouro: Tecnoprint.

Parlebás, P. (2012). Juegos, deporte y sociedades: léxico de praxiologia motriz. España: Editorial Paidotribo.

Peixoto, B. S. (2013). Dança, circo e risco: diálogos na cena contemporânea. Revista Aspas, 3(1), 85-95.

Resnick, R.; Halliday, D. e Walker, J. (2009). Fundamentos de física. Rio de Janeiro, Brasil: Livros Técnicos e Científicos.

Ricken, O. (2001). Zirkuspädagogik in der Kinder - und Jugendarbeit. Bielefeld, Deutschland: Diplomarbeit Universität Bielefeld, Fakultät für Pädagogik.

Rocha, G. (2016). Anjos e pernas: a "moça de circo” no imaginário artístico brasileiro. Visualidades, 14(1), 216-239.

Silva, D. O.; Souza, A.; Telles, C.; Krug, H. N.; e Kunz, E. (2016). Atividades circenses na escola: caminhos à organização didática a partir da concepção crítico-emancipatória. Licere, 19(1), 306-326.

Simon, A. (2000). Apprentis équilibristes. Revue EPS, 1, 97.

Suassuna, A. (2011). Iniciação à estética (11ํ ed.). Rio de Janeiro, Brasil: José Olympio.

Ward, S. (2001). Circus - the Illegitimate child. In Teaching Elemantary Physical Education - Human Kinetics (pp. 26-30). USA: Columbia.

\section{Notas}

1 Alusão às obras literárias de James Otis (1970) (título original: Toby Tyler; or Ten Weeks with a Circus), cuja primeira edição é datada de 1881, e de Franz Kafka (2015) (título original: Ein Hungerkünstler), publicada em 1922. Ambos os contos são ambientados no contexto dos espetáculos circenses.

2 Ilustrativo disso é o incrível número apresentado por Fu Xiuyu, que, em cima do monociclo, equilibra-se sobre a bola chinesa e com um dos pés arremessa tigelas de porcelana, equilibrando-as sobre a cabeça. Disponível em: https://www .youtube.com/watch?v=Uoxfv4dT40Q. Acesso em: 21 jan. 2018.

3 Segundo Ricken (2001), as bolas de equilíbrio geralmente medem de 60 a 70 centímetros. Todavia, informações atualizadas apontam uma maior variedade de tamanhos conforme o tamanho do praticante ou o objetivo a que se destina (cf. http://circos.com.pt/loja/26-bolas-de-equilibrio. Acesso em: 16 jan. 2018). 
4 Aparelho mais próximo da escalada, mas que por sua similitude com a corda bamba vem sendo utilizado pelos professores como aparelho de equilíbrio.

5 Referimo-nos ao episódio 86: O Palhaço que é? Disponível em: https://www.youtube.com/watch?v=wUQQuVCq3 $\mathrm{X} 4$

6 Segundo Fouchet (2006), número é um termo genérico que designa o conjunto de exercícios apresentados a partir de um tema e que constitui uma parte do espetáculo circense. É composto por uma entrada, desenvolvimento (variações de ritmos e rotinas) e saída, durando, em média, oito minutos.

7 Cf. Bode na corda bamba! Disponível em: https://www.youtube.com/watch?v=Qf4PXg0g8gE. Acesso em: 16 jan. 2018.

8 Sobre parte da história de vida de Marion Brede e sua trajetória artística, ver entrevista com a artista disponível em: h ttps://www.circonteudo.com/colunista/marion-brede-mulher-circense-uma-multidao-de-artes-circenses/. Acesso em: 16 jan. 2018.

9 Segundo Resnick, Halliday e Walker (2011), a condição de equilíbrio tem como requisitos: a) a soma vetorial das forças que agem sobre o corpo com valor nulo (vetor $\mathrm{F}_{\text {res }}=0$, equilíbrio de forças) e b) o valor nulo da soma vetorial de todos os torques externos que agem sobre o corpo (vetor torque $\mathrm{res}_{\mathrm{re}}=0$, equilíbrio de torques).

10 A respeito da pedagogia de outros aparelhos e outras modalidades circenses, sugerimos consultar os livros: Introdução à Pedagogia das Atividades Circenses, volume 1 (2008) e volume 2 (2010).

11 Considerando a força gravitacional (vetor $F_{g}$ ) como a soma vetorial das forças que agem sobre todos os elementos (átomos) de um corpo, podemos considerar que a $\mathrm{F}_{\mathrm{g}}$ age efetivamente sobre um único ponto, o centro de gravidade (CG) e, consequentemente, este coincide com o centro de massa $(\mathrm{CM})$ do corpo $\left(\mathrm{X}_{\mathrm{CG}}=\mathrm{X}_{\mathrm{CM}}\right)$ (Resnick, Halliday e Walker, 2011, p. 5).

12 Vídeos que podem ser de utilidade para o ensino da bola de equilíbrio:

Número artístico de The Rogge Sisters: https://www.youtube.com/watch?v=tW0GPo3ZKyg

Cirque du Soleil - Drálion: https://www.youtube.com/watch?v=kT7AtqOz6c4

Número de dança sobre a bola: https://www.youtube.com/watch?v=StvEdfXe1MY

Número de monociclo e bola: https://www.youtube.com/watch?v=0wniYjyFkA0 